\title{
Transcriptional activity of transposable elements in maize
}

\author{
Carlos M Vicient
}

\begin{abstract}
Background: Mobile genetic elements represent a high proportion of the Eukaryote genomes. In maize, 85\% of genome is composed by transposable elements of several families. First step in transposable element life cycle is the synthesis of an RNA, but few is known about the regulation of transcription for most of the maize transposable element families. Maize is the plant from which more ESTs have been sequenced (more than two million) and the third species in total only after human and mice. This allowed us to analyze the transcriptional activity of the maize transposable elements based on EST databases.

Results: We have investigated the transcriptional activity of 56 families of transposable elements in different maize organs based on the systematic search of more than two million expressed sequence tags. At least $1.5 \%$ maize ESTs show sequence similarity with transposable elements. According to these data, the patterns of expression of each transposable element family is variable, even within the same class of elements. In general, transcriptional activity of the gypsy-like retrotransposons is higher compared to other classes. Transcriptional activity of several transposable elements is specially high in shoot apical meristem and sperm cells. Sequence comparisons between genomic and transcribed sequences suggest that only a few copies are transcriptionally active.

Conclusions: The use of powerful high-throughput sequencing methodologies allowed us to elucidate the extent and character of repetitive element transcription in maize cells. The finding that some families of transposable elements have a considerable transcriptional activity in some tissues suggests that, either transposition is more frequent than previously expected, or cells can control transposition at a post-transcriptional level.
\end{abstract}

\section{Background}

Transposable elements (TEs) are DNA sequences that move from one location to another within the genome or can produce copies of themselves. Eukaryotic TEs are divided into two classes, according to whether their transposition intermediate is RNA (class I) or DNA (class II). Each class contain elements that encode functional products required for transposition (autonomous) and elements that only retain the cis sequences necessary for recognition by the transposition machinery (non-autonomous). Class I elements can be divided into several subclasses: SINEs, LINEs, long terminal repeat (LTR) retrotransposons and TRIMs (Terminal-repeat Retrotransposons In Miniature), which are LTR nonautonomous elements [1]. Class II elements comprise autonomous and non-autonomous transposons,

Correspondence: cvsgmp@cid.csic.es

Departament of Molecular Genetics, Centre for Research in Agricultural Genomics, CSIC (IRTA-UAB), Jordi Girona, 18, 08034 Barcelona, Spain including the MITEs (Miniature Inverted-repeat Transposable Elements) [2].

TEs are major components of most eukaryotic genomes and are particularly abundant in plants. TEs represent $80 \%$ of the maize and $90 \%$ of wheat genomes [3]. All the classes of TEs found in Eukaryotes are also present in plant genomes, but LTR retrotransposons are the most abundant in terms of copy number and percentage of genome [4]. 95\% of maize TEs are LTR retrotransposons [5].

TEs play an important role in genome and gene evolution. TE insertion can disrupt genes and mediate chromosome rearrangements and can provide alternative promoters, exons, terminators and splice junctions [6]. Several rice genes contain TE derived sequences [7]. However, TE influence in gene expression is not restricted to physical modification of chromosomes. TEs were first characterized in maize as gene "controlling elements" [8]. Maize "controlling elements" change the 
expression of some genes due to the transcription of non-coding RNAs (ncRNA) from the transposon promoters which contribute to the epigenetic regulation of neighbouring genes through mechanisms such as RNAi, transcriptional interference and anti-silencing [9]. The methylation of a SINE element close to the FWA gene, a gene submitted to imprinting, allows the proper epigenetic control in Arabidopsis thaliana [10]. TEs also produce short double-stranded RNAs (dsRNAs) which contribute to the epigenetic gene regulation. Analyses in maize, tobacco, wheat or rice have shown that transcriptional readout from retrotransposon LTRs may generate sense and antisense transcripts of adjacent genes, altering their expression [11]. Given the large number of retrotransposon copies in plant genomes and their frequent location near genes, it becomes clear the high potential impact of the TE transcription on the expression of the nearby genes [12,13]. For this reason, TE transcription was believed to be severely repressed in plants. This point of view was supported by the fact that during long time transcription activity was only demonstrated for a few plant TEs, and only activated under certain precise circumstances as, for example, pathogen infection, physical injuries or different abiotic stresses $[14,15]$. Inactivity of TEs may be due to the accumulation of mutations that have altered their structure. However, although transpositionally inactive due to insertions, deletions, rearrangements or mutations, some copies of the TEs may retain the capacity to direct transcription from their own promoters. In addition to the direct inactivation, cells have also developed mechanism for TE control including silencing by DNA methylation or the small RNA pathways [16]. TEs producing doublestranded or aberrant RNAs are silenced by a post-transcriptional gene silencing mechanism (PTGS) and active TEs are inactivated by transcriptional gene silencing (TGS) [17].

Despite mutations and cell control, TEs manage to be transcriptionally and transpositionally active. Phylogenetic analysis of TE families in maize revealed recent events of extreme TE proliferation [18] and recent transposition activity has also been demonstrated in rice [19]. The use of sensitive techniques for gene expression analysis like deep transcriptome sequencing provide increasing data on the presence of TE-transcripts in several plants and cell types [20-23].

Maize is the plant species from which more ESTs have been sequenced and the third species only after human and mice [24]. More than two million maize ESTs have been sequenced from many libraries corresponding to several maize organs, developmental stages and conditions. It provides a strong basis for the development of computer-based procedures for the in silico analysis of expression profiles. The present work aimed to produce a body map of TE transcription in maize plants. We show that the fraction of TE-related transcripts varies greatly among TE classes and among organs.

\section{Results}

\section{Maize TEs are widely represented in EST databases}

The number of ESTs in a large transcript database can be used to estimate relative transcriptional rates. More than two million maize EST sequences are deposited in the NCBI EST database (Zm-dbEST). Such a large amount of sequences provides an opportunity to perform virtual analysis of gene expression in this species. We used a representative sequence of 56 well-characterized TEs (available in the repeats and retrotransposon databases) to query BLASTN against the maize EST database (Zm-dbESTs). 1,5\% of the total maize ESTs (25.282 sequences) showed significant sequence homology $\left(\mathrm{e}\right.$-value $<1 \mathrm{E}^{-20}$ ) with one of the 56 analysed TE families (Additional file 1).

Considering the different TE classes separately, the average number of TE-ESTs obtained for gypsy-like LTR retrotransposons (gypsy) is more than three folds higher than for any other TE class, followed by copialike LTR retrotransposons (copia) and CACTA (Figure 1). The values within each TE class have a large variability. For example, among gypsy elements, Prem has 4310

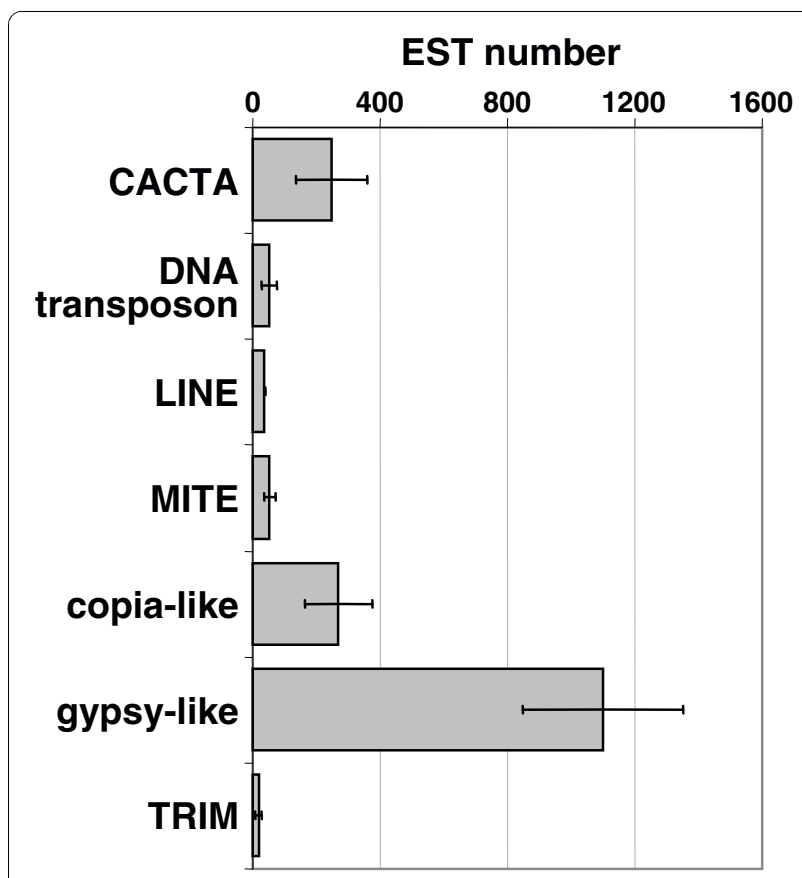

Figure 1 Transcription levels of the different TE classes Number of ESTs in maize databases showing similarity to TEs of different classes. Bars are the average number of ESTs showing similarity to the different members of the indicated TE class and the error bars are the standard errors. 
ESTs and jaws only two, and among copia elements Opie has 2296 and Hopscotch only one. However, the predominance of gypsy elements is not a result of high presence in EST databases of one or a few families, but generally most of gypsy families have a higher level of transcription compared with other elements. The comparison of the number of TE-ESTs of the families of copia and gypsy elements show a clear overall greater presence of gypsy families in databases (Table 1). Thus, while seven gypsy families have over a thousand TEESTs, only Opie exceeds this value among copia elements.

Previous works suggest that a negative correlation exists between retrotransposon copy numbers and transcription levels [25]. We compared the copy numbers of each TE family with the numbers of ESTs and we did not find correlation (positive or negative) $(r=0.209)$ (Figure 2). There are TE families with low copy numbers and several ESTs (Flip has 263 copies and 704 ESTs), and TE families with high copy numbers and few ESTs (Ji has 7.650 copies and only 209 ESTs). The lack of correlation between copy and EST numbers is also an indication that no extensive genomic contamination is present in the maize dbEST. We also checked for possible correlations between copy number and EST numbers looking for each of the libraries individually and we found no significant correlations in any of them (data not shown).

The distribution of the EST matches along the TE sequence was examined (Additional file 2). The EST distribution was variable depending on the TE element family, but a general similar behaviour was observed within classes. For example, in LINEs, most of the ESTs showed similarity with the 3'end. On the other hand, in LTR retrotransposons and TRIMs, most of the ESTs are similar to the LTR regions. These non-random distribution is probably a consequence of the different transcription mechanism characteristic of each TE family.

TE families are comprised by hundreds or thousands of copies inserted in the genome. A question arises of how many of these copies are transcriptionally active. Are the TE transcripts produced by several copies or only by one or a few of them? In order to answer this question we aligned randomly selected genomic sequences and transcribed sequences of some of the TE families and we constructed phylogenetic trees (an example is in Figure 3 and more data are available in Additional file 3). Several clades of genomic sequences were detected, some of them composed by many closely related copies which probably represent recent transposition bursts. EST sequences are located only in a few of these clades, which indicate that only few evolutionary branches of the TEs have retained transcriptional competence. A similar situation was observed in all families analysed (Additional file 3). It does not exist a correlation between the active subfamily and transcription in certain organs. These results also suggest that genomic contamination in the EST databases, if exists, is negligible and that the observed EST frequencies are indicative of transcriptional activity of the TE families in maize.

\section{Profiles of TE transcription in different maize organs and conditions}

Many of the maize ESTs were obtained from libraries constructed with RNA extracted from dissected organs. This allows us to study organ-specific expression of the different TE families using a "virutal northern" strategy based on the abundance of the ESTs on each library. ESTs matching the TEs were divided according to the library they were sequenced from. Due that for some of the libraries the number of ESTs was not enough to guarantee a deep analysis, we grouped the libraries constructed from the same or related organs. Each group of libraries contains a different number of sequences, so, direct comparison between organs is not possible. A normalization process was done dividing the matches by the total number of sequences in each of the groups. The resulting numbers reflect the overall expression level of each family among the different organs and conditions tested. As a result, we obtained expression values for each of the 56 TE families in 12 different organs or conditions (Figure 4). As a control, we used the same analysis for four genes of known and precise patterns of expression: zein, es1, mgs 2 and PEP1. In all cases the analysis gave us the expected patterns of expression for all marker genes, zein in endosperm, es 1 in ovary, $m g s 2$ in male flower and PEP1 in leaves. The TE expression patterns vary considerably between and within classes. Whereas many TE families show low levels of expression in all organs and conditions, others have especially high levels in certain organs. Several retrotransposons seem to be specially expressed in apical meristem like Prem or Danelle. Giepum, Flip, Prem1 and Shadowspawn are specially expressed in cultured cells and Prem 1 is also highly represented in ovary. Considering all the TE classes, shoot apical meristem and cell culture are clearly the organs with a higher presence of TEESTs, followed by ovary and male flower (Figure 5). As we showed previously (Figure 1), gypsy elements are the most abundantly represented in the EST databases, and this is also true if we consider separately the different organs. CACTA are specially represented in SAM and ovary, DNA transposons in cultured cells, LINEs in ovary, and TRIMs in ovary.

Relatively high number of TE-ESTs have been observed in male reproductive organs (Figure 5). This is interesting because this organ can potentially lead to the germ line cells, allowing a possible transposition event 
Table 1 TE families analysed in this study

\begin{tabular}{|c|c|c|c|c|c|c|}
\hline Class & Family & $\%$ genome & Copy number & Total Size & LTR size & ESTs \\
\hline \multirow[t]{3}{*}{ САCTA } & $\mathrm{En} / \mathrm{Spm}$ & n.a. & n.a. & 8270 & - & 46 \\
\hline & Misfit & n.a. & n.a. & 10630 & - & 430 \\
\hline & Yote & n.a. & n.a. & 12259 & - & 267 \\
\hline \multirow[t]{8}{*}{ DNA Transposon } & $\mathrm{Ac} / \mathrm{Ds}$ & n.a. & n.a. & 4565 & - & 28 \\
\hline & Doppia & n.a. & n.a. & 8463 & - & 218 \\
\hline & Jittery & n.a. & n.a. & 3916 & - & 6 \\
\hline & Mutator & n.a. & n.a. & 4998 & - & 30 \\
\hline & $M x$ & n.a. & n.a. & 3731 & - & 3 \\
\hline & PIF & n.a. & n.a. & 3712 & - & 71 \\
\hline & rDT & n.a. & n.a. & 704 & - & 12 \\
\hline & Shooter & n.a. & n.a. & 5060 & - & 54 \\
\hline \multirow[t]{3}{*}{ LINE } & Cin4 & n.a. & n.a. & 6822 & - & 34 \\
\hline & Colonist1 & n.a. & n.a. & 1658 & - & 37 \\
\hline & Colonist2 & n.a. & n.a. & 2575 & - & 42 \\
\hline \multirow[t]{7}{*}{ MITE } & Frequent flyer & n.a. & n.a. & 526 & - & 119 \\
\hline & Heart breaker & n.a. & n.a. & 315 & - & 55 \\
\hline & Heart healer & n.a. & n.a. & 185 & - & 122 \\
\hline & $\mathrm{mPIF}$ & n.a. & n.a. & 343 & - & 55 \\
\hline & Pangrangja & n.a. & n.a. & 607 & - & 18 \\
\hline & Stowaway & n.a. & n.a. & 178 & - & 2 \\
\hline & Tourist & n.a. & n.a. & 150 & - & 4 \\
\hline \multirow[t]{14}{*}{ LTR retrotransposon (Copia) } & Bs1 & n.a. & n.a. & 3.203 & 302 & 15 \\
\hline & Eninu & n.a. & n.a. & 7.219 & 1.386 & 102 \\
\hline & Fourf & 0.69 & 293 & 6.888 & 1.210 & 133 \\
\hline & Giepum & 0.55 & 233 & 11.756 & 1.689 & 559 \\
\hline & Hopscotch & n.a. & n.a. & 4.884 & 227 & 1 \\
\hline & $\mathrm{Ji}$ & 18 & 7650 & 12085 & 1.481 & 209 \\
\hline & Machiavelli & 0.48 & 204 & 6.153 & 857 & 81 \\
\hline & Milt & 2 & 850 & 9.344 & 729 & 424 \\
\hline & Opie & 16 & 6800 & 8880 & 1.256 & 1488 \\
\hline & Raider & n.a. & n.a. & 5.865 & 465 & 34 \\
\hline & Rire1 & 0.48 & 204 & 7.815 & 1.270 & 176 \\
\hline & Ruda & 1.64 & 697 & 6.431 & 1.415 & 507 \\
\hline & Stonor & 0.07 & 29 & 4.542 & 560 & 42 \\
\hline & Victim & 0.14 & 59 & 5.427 & 101 & 6 \\
\hline \multirow[t]{16}{*}{ LTR retrotransposon (gypsy) } & CentA & n.a. & n.a. & 4.634 & 1.303 & 147 \\
\hline & Cinful & 5 & 2125 & 9.568 & 653 & 2181 \\
\hline & CRM & n.a. & n.a. & 7.571 & 930 & 1078 \\
\hline & Dagaf & 1.17 & 497 & 10.197 & 3.579 & 612 \\
\hline & Danelle & 4 & 1700 & 15.397 & 4.602 & 2601 \\
\hline & Diguus & 0.69 & 293 & 11.679 & 4.366 & 634 \\
\hline & Flip & 0.62 & 263 & 13.555 & 5.928 & 704 \\
\hline & Grande & 3 & 1275 & 13.769 & 631 & 365 \\
\hline & Gyma & 3 & 1275 & 12.246 & 3.850 & 520 \\
\hline & Huck & 15 & 6375 & 11312 & 1.800 & 322 \\
\hline & Jaws & 0.14 & 59 & 6.074 & 384 & 1 \\
\hline & Kake & 0.07 & 29 & 5.914 & 173 & 39 \\
\hline & Prem & 5 & 2125 & 9.469 & 1.314 & 3806 \\
\hline & Prem1 & 1.37 & 582 & 10.397 & 3.383 & 2198 \\
\hline & Shadowspawn & 2 & 850 & 11.526 & 469 & 399 \\
\hline & Tekay & 1.17 & 497 & 12.786 & 3.396 & 395 \\
\hline
\end{tabular}


Table 1 TE families analysed in this study (Continued)

\begin{tabular}{lllllll}
\hline & Xilon & 4 & 1700 & 11.514 & 2.467 & 1865 \\
& Zeon & 8 & 3400 & 7.459 & 698 & 1930 \\
\hline TRIM & Cassandra/TIM-1 & 1.10 & 467 & 734 & 260 & 18 \\
& Magellan & n.a. & n.a. & 1313 & - & 1 \\
& ZmTRIM & n.a. & n.a. & 809 & - & 36 \\
\hline
\end{tabular}

to be inherited. However, "Male flower" group is composed by sequences obtained from six cDNA libraries obtained from dissected anther, pollen, sperm cell, tassel and tassel primordium. So, we decided to examine in more detail the origin of the TE-ESTs for this category doing the same analysis, but considering separately the different libraries. We observed that the majority of the TE-ESTs were originated in the sperm cell library (Figure 6A). Gypsy-like retrotransposons are specially represented in the male flower category and most of the ESTs were originated from the sperm cell library. Looking at the different gypsy-like families individually, predominance of sperm cell was observed in all of them (Figure 6B).

\section{Discussion}

"Virtual northern" analysis provides an easy and cheap alternative to the study of transcriptional profiling. An advantage of EST profiling compared with other methods is that it does not require prior knowledge of the gene sequences. The accuracy of "virtual northern" analyses will depend on the diversity of biological samples and in the number of sequence tags to provide sufficient depth to identify low-abundant transcripts. An

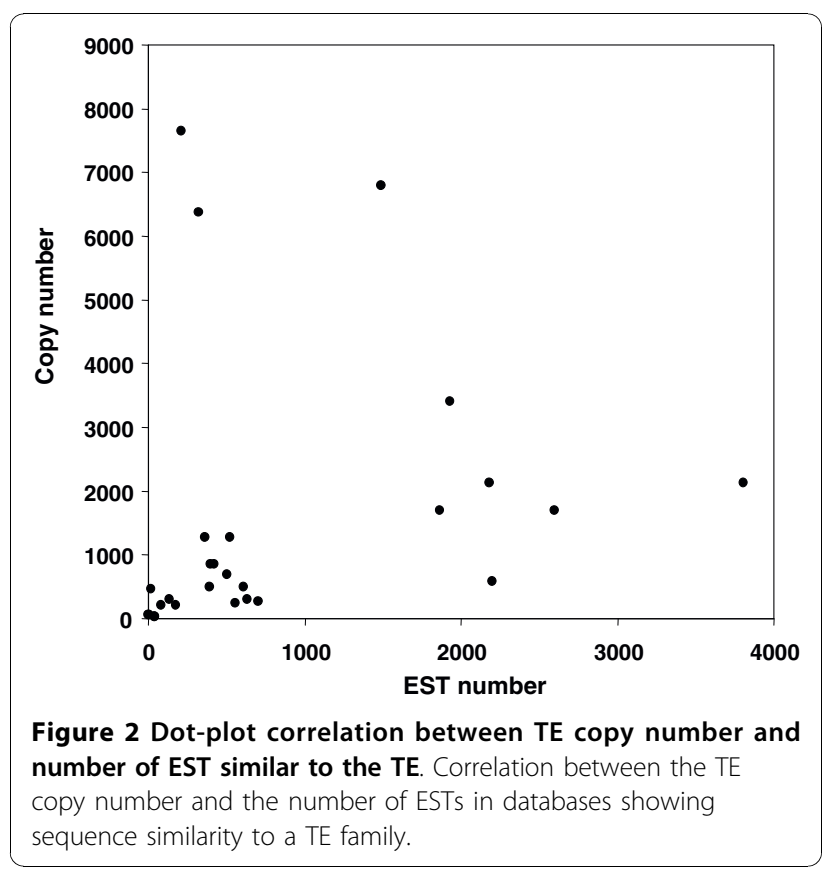

additional problem will be the possibility to distinguish between closely related genes in the basis of partial sequences. EST profiling have been used for the identification of reference genes for quantitative RT-PCR normalization in wheat [26] and barley [27], expression profiling of storage-protein gene families in wheat [28], identification of differentially expressed transcripts from sugarcane maturing stem [29], or the identification of cancer gene-markers in humans [30]. The application of EST profiling to maize TEs is particularly appropriate. First, the analysis of TE families, and not single genes, virtually eliminates the problem of distinguishing between closely related sequences. Second, maize is the third organism in number of ESTs, and, finally, several of the cDNA libraries were constructed from precise, well-defined, dissected organs. The applicability of EST profiling in maize is demonstrated by the expected results for some marker genes (figure 4). One possible problem is the presence of sequences originated from

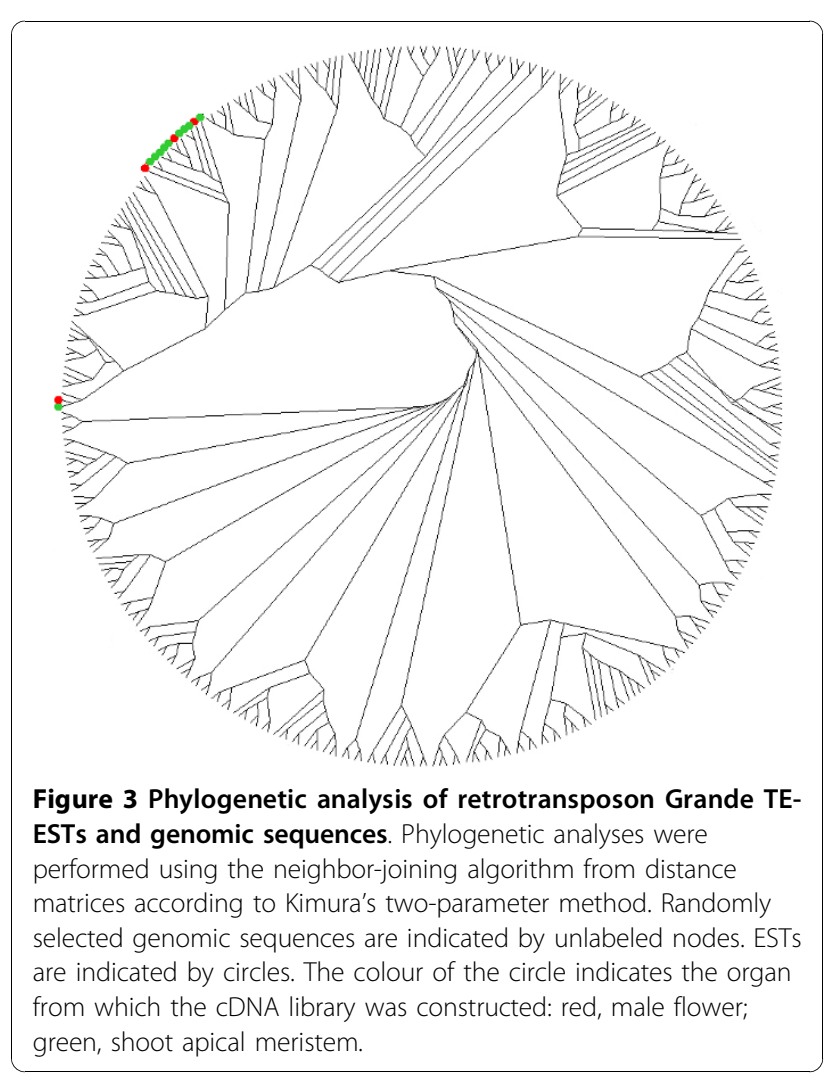




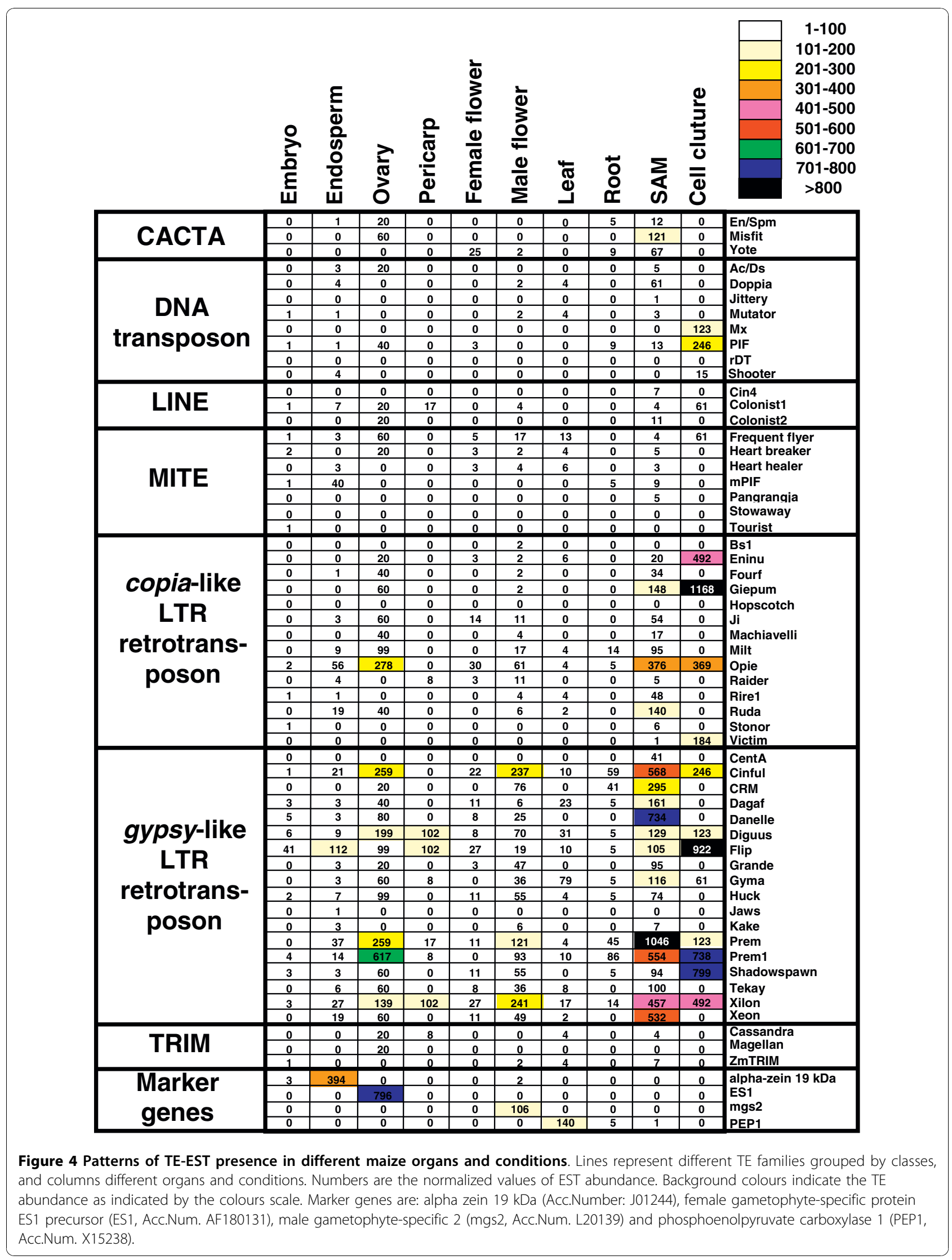




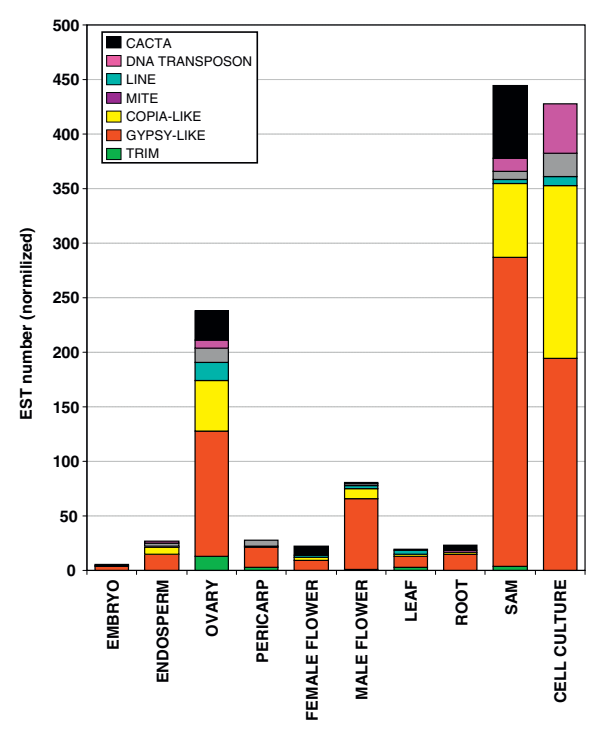

Figure 5 Presence of TE-ESTs of different TE classes in maize organs and conditions. Average presence of ESTs homologous to $T E$ in different maize organs and conditions.

contaminant genomic DNA in the EST collections. This problem is especially serious in the case of TEs because some of them are present in high copy numbers in the genome. Although we cannot totally exclude the presence of some genomic contamination, our results indicate that, if any, it may be considered anecdotic (Figure 2).

Once integrated in the genome, TEs accumulate mutations and become transpositionally inactive. However, even partial or rearranged TE copies may retain their capacity to initiate transcription. Cells have active mechanisms to protect their genome integrity against TE activity including transcriptional silencing [31] and short-interfering RNAs (siRNAs) [32]. Under certain circumstances some TEs can escape this cell control and transcribe and, sometimes, transpose [19]. For example, different TE families are transcribed in response to biotic or abiotic stresses or in cell culture [33-37]. In addition to these "stress response" transcription, increasing data demonstrate that some TEs may have at least low transcriptional activities under normal circumstances in plant life. For example, transcription in leaves has been demonstrated for barley BARE, maize Grande and tomato Rider retrotransposons, and in different sorghum TEs [38-41]. Different EST based analysis, including the data presented here, demonstrate the presence of TEtranscripts in several organs and cell types [20-22,42,43]. According to our data, at least $1.5 \%$ of the ESTs correspond to TEs. This is an underestimation because only well characterized maize TEs were considered in our analysis and because ESTs libraries only contain data on polyadenylated mRNAs and it is not clear which percentage of TE transcripts contain a polyA track. For example, it has been estimated that only $15 \%$ the transcripts of the barley retrotransposon BARE1 are polyadenylated [44]. In any case, the percentage is different according to the organs analysed ranging from $7.7 \%$ in SAM and $6.2 \%$ in cultured cells, to only $0.2 \%$ in female flowers and $0.1 \%$ in embryo.

TE transcripts are specially abundant in SAM, cultured cells (Figure 4; [23]) and sperm cells (Figure 5; [31,45-47]). A common feature of SAM, pollen and cell cultures is that they contain pluripotent cells. Animal totipotent cells like oocytes and two-cell mouse embryos also exhibit high levels of TE transcription [48]. The acquisition of totipotency depends, among other things, on epigenetic reprogramming [49] and activation of TEs has also been associated with reductions on DNA methylation [50]. For example, DNA in plant cultured cells undergoes hypomethylated and these cells show a transcriptional activation of specific TEs [31]. Tobacco Tnt1 retrotransposon is silenced when introduced in Arabidopsis, but reversion of Tnt1 silencing is obtained when the number of Tnt1 elements is reduced to two by genetic segregation [51]. Microarray expression profiling of Arabidopsis mature pollen revealed that many of the genes involved in siRNA biogenesis and silencing are not expressed in pollen or expressed at low levels [52]. Although epigenetic changes may explain activation of certain TEs in some tissues, not all TE families accumulate equally in SAM or sperm cells, suggesting that the phenomenon requires some family specific mechanisms rather than simply being the result of a genome-wide activation of retrotransposons. One possible explanation may be the presence of cis specific signals in the TE promoter that may enhance their expression in certain cells. For example, pollen promoter specific signals have been detected in the LTR of Grande (personal unpublished data).

\section{Conclusions}

The use of powerful high-throughput sequencing methodologies allowed us to elucidate the extent and character of repetitive element transcription in maize cells. Next-generation sequencing of transcriptomes and genomes will enable further studies on TE transcription and their consequences.

\section{Methods}

\section{Data sources and analysis}

Model TE sequences were obtained from the TIGR Plant Repeat Databases [53], Retrotransposon Database [54] and GeneBank. Only well characterized elements were included in our analysis (Table 1). Model sequences were compared with the maize (Zea mays L.) entries in NCBI dbEST release 092509 [24], which 


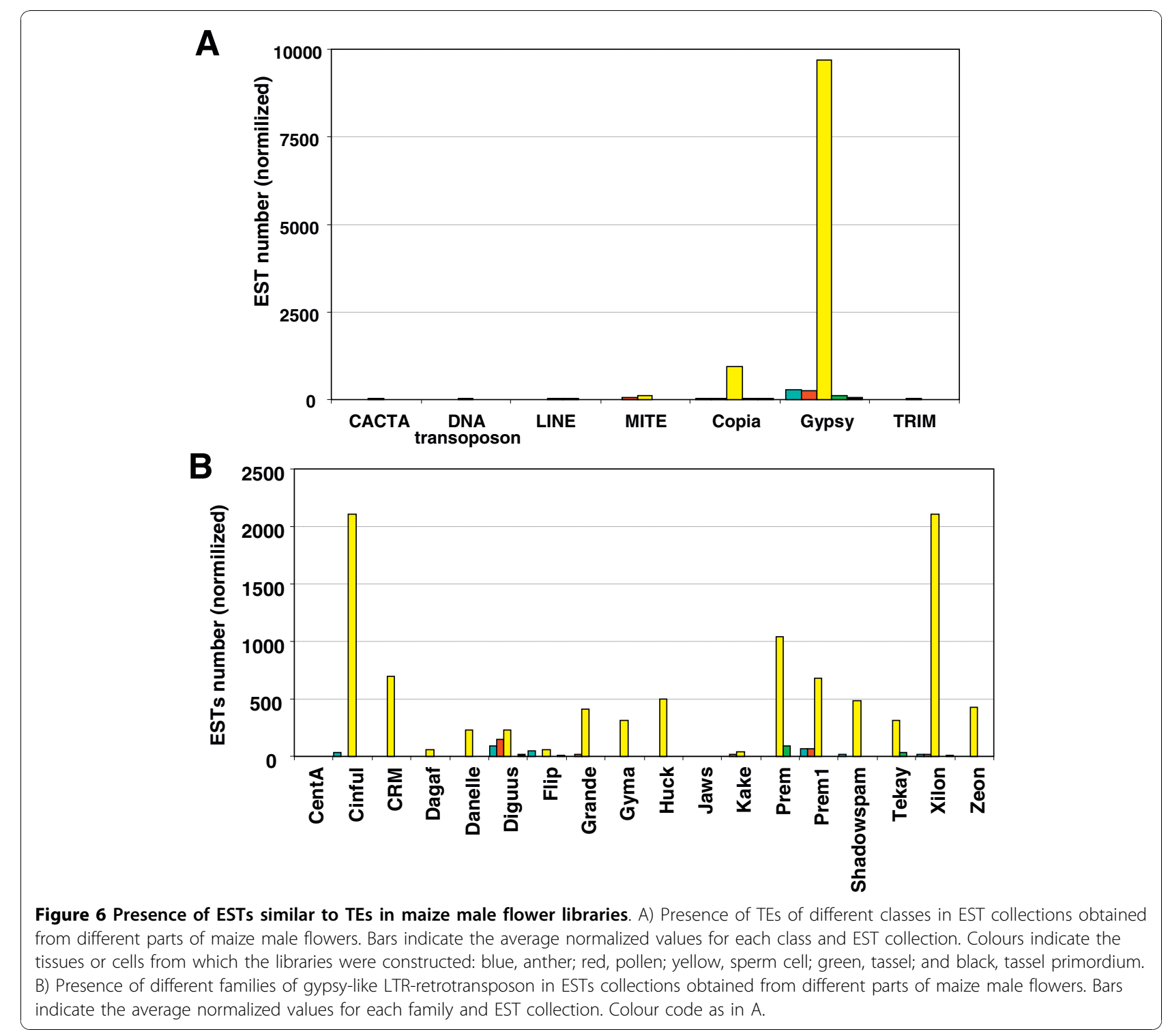

contained 2,018,634 sequences from 315 cDNA libraries, using BLASTN analysis [55]. BLAST analysis were performed using an expected threshold of 10 , a word size of 11 , a match/mismatch of 2-3 and gap cost existence of 5 and extension of 2 . We only considered positive such sequences showing an e-value $<1 \mathrm{E}^{-20}$. For organspecific expression analysis libraries in the UniGene data set constructed from the same (or related) organ(s) were assigned into common pools. Libraries with insufficient information regarding the source organ or constructed from mixed parts of the plant were excluded from the analysis. These efforts resulted in organ groupings each containing different numbers of libraries and ESTs (Table 2). The differences in the clone numbers between organ groups do not allow a direct comparison of EST numbers. A normalization process was done dividing the number of ESTs by the total number of sequences in the organ group. Normalization values were expressed as 1 per 10.000 .

Sequence alignments were performed using CLUSTALW and phylogenetic trees using neighbour joining method. Graphic representation of phylogenetic trees were prepared using Dendroscope v.2.7.4 [56].

\section{List of Abbreviations}

TE: transposable element; TE-EST: EST: with sequence similarity to a transposable element; LTR: long terminal repeat; LINE: long interspersed transposable elements; MITE: Miniature Inverted Transposable Element; TRIM: Terminal-repeat Retrotransposons In Miniature. 
Table 2 Organ/condition maize EST databases used in this analysis

\begin{tabular}{lcc}
\hline Organ/conditions & Number of libraries & Number of ESTs \\
\hline Embryo & 14 & 23.334 \\
Endosperm & 15 & 67.625 \\
Ovary & 8 & 33.604 \\
Pericarp & 4 & 10.440 \\
Female flower & 15 & 49.972 \\
Male flower & 12 & 43.842 \\
Leaves & 31 & 38.133 \\
Root & 20 & 39.810 \\
Shoot apical meristem & 15 & 593.966 \\
Cell culture & 6 & 14.058
\end{tabular}

\section{Additional material}

\section{Additional file 1: Maize ESTs displaying sequence homology with} TEs.

Additional file 2: Distribution of homologies of the maize TE-ESTs along the corresponding TE sequences. Schematic representation of the regions of the different TE families showing similarity to a maize EST. Bar in the top represent the TE element and smaller bars on the bottom the different ESTs. When the number of ESTs was high only the ESTs showing higher similarities were represented.

Additional file 3: Phylogenetic analysis of TE-ESTs and genomic sequences of different transposable elements. Phylogenetic analyses were performed using the neighbor-joining algorithm from distance matrices according to Kimura's two-parameter method. Randomly selected genomic sequences are indicated by the accession number of the sequence from which were obtained. ESTs are indicated by their accession numbers. The position of the ESTs is also indicated by circles. The colours of the circles indicate the organ from which the cDNA library was constructed.

\section{Acknowledgements}

I am in agreement with Josep M Casacuberta for critical reading the manuscript.

\section{Authors' contributions}

The author did all the analyses and wrote the manuscript.

Received: 26 March 2010 Accepted: 25 October 2010

Published: 25 October 2010

\section{References}

1. Wicker T, Sabot F, Hua-Van A, Bennetzen UL, Capy P, Chalhoub B, Flavell A, Leroy $P$, Morgante $M$, Panaud O, Paux E, SanMiguel P, Schulman AH: A unified classification system for eukaryotic transposable elements. Nature Rev Genet 2007, 8:973-982.

2. Feschotte $C$, Jiang N, Wessler SR: Plant transposable elements: where genetics meets genomics. Nat Genet 2002, 3:329-341.

3. Devos KM, Ma J, Pontaroli AC, Pratt LH, Bennetzen JL: Analysis and mapping of randomly chosen bacterial artificial chromosome clones from hexaploid bread wheat. Proc Natl Acad Sci USA 2005, 102:19243-19248.

4. Vitte C, Bennetzen JL: Analysis of retrotransposon structural diversity uncovers properties and propensities in angiosperm genome evolution. Proc Natl Acad Sci USA 2006, 103:17638-17643.
5. Haberer G, Young S, Bharti AK, Gundlach H, Raymond C, Fuks G, Butler E, Wing RA, Rounsley S, Birren B, Nusbaum C, Mayer KF, Messing J: Structure and architecture of the maize genome. Plant Physiol 2005, 139:1612-1624.

6. Bennetzen JL: Transposable element contributions to plant genome evolution. Plant Mol Biol 2000, 42:251-269.

7. Sakai H, Tanaka T, Itoh T: Birth and death of genes promoted by transposable elements in Oryza sativa. Gene 2007, 392:59-63.

8. McClintock B: The significance of responses of the genome to challenge. Science 1984, 226:792-801.

9. Zaratiegui M, Irvine DV, Martienssen RA: Noncoding RNAs and gene silencing. Cell 2007, 128:763-776.

10. Kinoshita Y, Saze H, Kinoshita T, Miura A, Soppe W, Koornneef M, Kakutani T: Control of FWA gene silencing in Arabidopsis thaliana by SINE-related direct repeats. Plant J 2007, 49:38-45.

11. Wang GL, Ruan DL, Song WY, Sideris S, Chen L, Pi LY, Zhang S, Zhang Z, Fauquet C, Gaut BS, Whalen MC, Ronald PC: Xa21D encodes a receptorlike molecule with a leucine-rich repeat domain that determines racespecific recognition and is subject to adaptive evolution. Plant Cell 1998, 10:765-780.

12. Le $\mathrm{Q}$, Melayah D, Bonnivard E, Petit M, Grandbastien M: Distribution dynamics of the Tnt1 retrotransposon in tobacco. Mol Genet Genom 2007, 278:1617-4615

13. Miyao A, Tanaka K, Murata K, Sawaki H, Takeda S, Abe K, Shinozuka Y, Onosato K, Hirochika H: Target site specificity of the Tos 17 retrotransposon shows a preference for insertion within genes and against insertion in retrotransposon rich regions of the genome. Plant Cell 2003, 15:1771-1780.

14. Grandbastien MA: Activation of plant retrotransposons under stress conditions. Trends Plant Sci 1998, 3:181-187.

15. Takeda S, Sugimoto K, Otsuki H, Hirochika H: Transcriptional activation of the tobacco retrotransposon Tto1 by wounding and methyl jasmonate. Plant Mol Biol 1998, 36:365-376.

16. Casacuberta JM, Santiago N: Plant LTR-retrotransposons and MITEs: control of transposition and impact on the evolution of plant genes and genomes. Gene 2003, 311:1-11.

17. Okamoto $\mathrm{H}$, Hirochika $\mathrm{H}$ : Silencing of transposable elements in plants. Trends Plant Sci 2001, 6:527-534.

18. Kronmiller BA, Wise RP: TEnest: automated chronological annotation and visualization of nested plant transposable elements. Plant Physiol 2008, 146:45-59.

19. Picault N, Chaparro C, Piegu B, Stenger W, Formey D, Llauro C, Descombin J, Sabot F, Lasserre E, Meynard D, Guiderdoni E, Panaud O: Identification of an active LTR retrotransposon in rice. Plant J 2009, 58:754-765.

20. Vicient $C M$, Jääskeläinen $M J$, Kalendar $R$, Schulman $A H$ : Active retrotransposons are a common feature of grass genomes. Plant Physiol 2001, 125:1283-1292.

21. de Araujo PG, Rossi M, de Jesus EM, Saccaro NL Jr, Kajihara D, Massa R, de Felix JM, Drummond RD, Falco MC, Chabregas SM, Ulian EC, Menossi M, Van Sluys MA: Transcriptionally active transposable elements in recent hybrid sugarcane. Plant J 2005, 44:707-717.

22. Lopes FR, Carazzolle MF, Pereira GA, Colombo CA, Carareto CM: Transposable elements in Coffea (Gentianales: Rubiacea) transcripts and their role in the origin of protein diversity in flowering plants. Mol Genet Genom 2008, 279:385-401.

23. Ohtsu K, Smith MB, Emrich SJ, Borsuk LA, Zhou R, Chen T, Zhang X, Timmermans MC, Beck J, Buckner B, Janick-Buckner D, Nettleton D, Scanlon MJ, Schnable PS: Global gene expression analysis of the shoot apical meristem of maize (Zea mays L.). Plant J 2008, 52:391-404.

24. dbEST: database of "Expressed Sequence Tags". [http://www.ncbi.nlm.nih. gov/dbEST//

25. Meyers BC, Tingey SV, Morgante M: Abundance, distribution, and transcriptional activity of repetitive elements in the maize genome. Genome Res 2001, 11:1660-1676.

26. Paolacci AR, Tanzarella OA, Porceddu E, Ciaffi M: Identification and validation of reference genes for quantitative RT-PCR normalization in wheat. BMC Mol Biol 2009, 10:11

27. Faccioli P, Paolo Ciceri GP, Provero P, Stanca AM, Morcia C, Terzi V: A combined strategy of "in silico" transcriptome analysis and web search engine optimization allows an agile identification of reference genes 
suitable for normalization in gene expression studies. Plant Mol Biol 2007, 63:679-688.

28. Kawaura K, Mochida K, Ogihara Y: Expression Profile of Two StorageProtein Gene Families in Hexaploid Wheat Revealed by Large-Scale Analysis of Expressed Sequence Tags. Plant Physiol 2005, 139:1870-1880.

29. Casu RE, Dimmock CM, Chapman SC, Grof CP, Mclntyre CL, Bonnett GD, Manners JM: Identification of differentially expressed transcripts from maturing stem of sugarcane by in silico analysis of stem expressed sequence tags and gene expression profiling. Plant Mol Biol 2004, 54:503-517.

30. Reis EM, Ojopi EP, Alberto FL, Rahal P, Tsukumo F, Mancini UM, Guimarães GS, Thompson GM, Camacho C, Miracca E, Carvalho AL, Machado AA, Paquola AC, Cerutti JM, da Silva AM, Pereira GG, Valentini SR, Nagai MA, Kowalski LP, Verjovski-Almeida S, Tajara EH, Dias-Neto E, Bengtson MH, Canevari RA, Carazzolle MF, Colin C, Costa FF, Costa MC, Estécio MR, Esteves LI, Federico MH, Guimarães PE, Hackel C, Kimura ET, Leoni SG, Maciel RM, Maistro S, Mangone FR, Massirer KB, Matsuo SE, Nobrega FG, Nóbrega MP, Nunes DN, Nunes F, Pandolfi JR, Pardini MI, Pasini FS, Peres T, Rainho CA, dos Reis PP, Rodrigus-Lisoni FC, Rogatto SR, dos Santos A, dos Santos PC, Sogayar MC, Zanelli CF: Large-scale transcriptome analyses reveal new genetic marker candidates of head, neck, and thyroid cancer. Cancer Res 2005, 65:1693-1699.

31. Tanurdzic M, Vaughn MW, Jiang H, Lee TJ, Slotkin RK, Sosinski B, Thompson WF, Doerge RW, Martienssen RA: Epigenomic consequences of immortalized plant cell suspension culture. PLoS Biol 2008, 6:2880-2895.

32. Kasschau KD, Fahlgren N, Chapman EJ, Sullivan CM, Cumbie JS, Givan SA, Carrington JC: Genome-wide profiling and analysis of Arabidopsis siRNAs. PLoS Biol 2007, 5:e57.

33. Pouteau S, Huttner E, Grandbastien MA, Caboche M: Specific expression of the tobacco Tnt1 retrotransposon in protoplasts. EMBO J 1991, 10:1911-1918.

34. Hirochika H: Activation of tobacco retrotransposons during tissue culture. EMBO J 1993, 12:2521-2528.

35. Mhiri C, Morel JB, Vernhettes S, Casacuberta JM, Lucas H, Grandbastien MA: The promoter of the tobacco Tnt1 retrotransposon is induced by wounding and by abiotic stress. Plant Mol Biol 1997, 33:257-266.

36. Ramallo E, Kalendar R, Schulman AH, Martínez-lzquierdo JA: Reme1, a Copia retrotransposon in melon, is transcriptionally induced by UV light. Plant Mol Biol 2008, 66:137-150

37. Ueki N, Nishii I: Idaten is a new cold-inducible transposon of Volvox carteri that can be used for tagging developmentally important genes. Genetics 2008, 180:1343-1353.

38. Suoniemi A, Narvanto A, Schulman AH: The BARE-1 retrotransposon is transcribed in barley from an LTR promoter active in transient assays. Plant Mol Biol 1996, 31:295-306.

39. Gómez E, Schulman AH, Martínez-Izquierdo JA, Vicient CM: Integrase diversity and transcription of the maize retrotransposon Grande. Genome 2006, 49:558-562.

40. Cheng X, Zhang D, Cheng Z, Keller B, Ling HQ: A new family of Ty1-copialike retrotransposons originated in the tomato genome by a recent horizontal transfer event. Genetics 2009, 181:1183-1193.

41. Muthukumar B, Bennetzen JL: Isolation and characterization of genomic and transcribed retrotransposon sequences from sorghum. Mol Genet Genom 2004, 271:308-316.

42. Vicient $\mathrm{CM}$, Schulman $\mathrm{AH}$ : Copia-like retrotransposons in the rice genome: few and assorted. Genome lett 2002, 1:35-47.

43. Kashkush K, Feldman M, Levy AA: Transcriptional activation of retrotransposons alters the expression of adjacent genes in wheat. Nat Genet 2003, 33:102-106.

44. Chang W, Schulman AH: BARE retrotransposons produce multiple groups of rarely polyadenylated transcripts from two differentially regulated promoters. Plant J 2008, 56:40-50.

45. Skibbe DS, Fernandes JF, Medzihradszky KF, Burlingame AL, Walbot V: Mutator transposon activity reprograms the transcriptomes and proteomes of developing maize anthers. Plant J 2009, 59:622-633.

46. Nobuta K, Venu RC, Lu C, Belo A, Vemaraju K, Kulkarni K, Wang W, Pillay M, Green PJ, Wang GL, Meyers BC: An expression atlas of rice mRNAs and small RNAs. Nature Biotech 2007, 25:473-477.

47. Engel ML, Chaboud A, Dumas C, McCormick S: Sperm cells of Zea mays have a complex complement of mRNAs. Plant J 2003, 34:697-707.
48. Peaston AE, Evsikov AV, Graber JH, de Vries WN, Holbrook AE, Solter D, Knowles BB: Retrotransposons regulate host genes in mouse oocytes and preimplantation embryos. Dev Cell 2004, 7:597-606.

49. Roelen BA, Lopes SM: Of stem cells and gametes: similarities and differences. Curr Med Chem 2008, 15:1249-1256.

50. Lippman Z, May B, Yordan C, Singer T, Martienssen R: Distinct mechanisms determine transposon inheritance and methylation via small interfering RNA and histone modification. PLOS Biol 2003, 1:e67.

51. Pérez-Hormaeche J, Potet F, Beauclair L, Le Masson I, Courtial B, Bouché N, Lucas $\mathrm{H}$ : Invasion of the Arabidopsis genome by the tobacco retrotransposon Tnt1 is controlled by reversible transcriptional gene silencing. Plant Physiol 2008, 147:1264-1278.

52. Pina C, Pinto F, Feijó JA, Becker JD: Gene family analysis of the Arabidopsis pollen transcriptome reveals biological implications for cell growth, division control, and gene expression regulation. Plant Physiol 2005, 138:744-756.

53. TIGR Plant Repeat Databases. [http://www.tigr.org/tdb/e2k1/plant.repeats/].

54. Retrotransposon Database. [http://data.genomics.purdue.edu/ pmiguel/ projects/retros/].

55. NCBI blast. [http://blast.ncbi.nlm.nih.gov/Blast.cgi].

56. Huson DH, Richter DC, Rausch C, Dezulian T, Franz M, Rupp R: Dendroscope: An interactive viewer for large phylogenetic trees. $B M C$ Bioinf 22:460.

\section{doi:10.1186/1471-2164-11-601}

Cite this article as: Vicient: Transcriptional activity of transposable elements in maize. BMC Genomics 2010 11:601.

\section{Submit your next manuscript to BioMed Central and take full advantage of:}

- Convenient online submission

- Thorough peer review

- No space constraints or color figure charges

- Immediate publication on acceptance

- Inclusion in PubMed, CAS, Scopus and Google Scholar

- Research which is freely available for redistribution

Submit your manuscript at www.biomedcentral.com/submit
Ciomed Central 